\title{
Assessing energy supply security: Outage costs in private households
}

\author{
Aaron J. PRAKTIKNJO*, Alexander HÄHNEL and Georg ERDMANN \\ Department of Energy Systems, Berlin University of Technology, \\ Einsteinufer 25 (TA8), 10587 Berlin, Germany \\ *Corresponding author, Tel: +49-(0)30-314-79 329, Fax: +49-(0)30-314-78 728, \\ Email: aaron.j.praktiknjo@tu-berlin.de
}

\begin{abstract}
(C) 2011. This manuscript version is made available under the CC-BY-NC-ND 4.0 license http://creativecommons.org/licenses/by-nc-nd/4.0/
\end{abstract}
Please cite this article as: Praktiknjo, A., Hähnel, A., Erdmann, G. (2011): Assessing energy supply security: Outage costs in private households. In: Energy Policy, 39: 7825-7833. http://dx.doi.org/10.1016/j.enpol.2011.09.028

\begin{abstract}
The objective of this paper is to contribute to the topic of energy supply security by proposing a Monte Carlo-based and a survey-based model to analyze the costs of power interruptions. Outage cost estimations are particularly important when deciding on investments to improve supply security (e.g. additional transmission lines) in order to compare costs to benefits. But also, other policy decisions on measures that have direct or indirect consequences for the supply security (e.g. a phasing out of nuclear energy) need to be based on results from outage cost estimations. The main focus of this paper lies with residential consumers, but the model is applied to commercial, industrial and governmental consumers as well. There are limited studies that have approached the problem of evaluating outage cost. When comparing the results of these studies, they often display a high degree of diversification. As consumers have different needs and dependencies towards the supply of electricity because of varying circumstances and preferences, a great diversity in outage cost is a logical consequence. To take the high degree of uncertainties into account, a Monte Carlo simulation was conducted in this study for the case of private households in Germany.
\end{abstract}

Keywords: Blackout, Outage cost, Value of lost load

\section{Introduction}

In reaction to the events of the nuclear catastrophe in the Japanese prefecture Fukushima, the German government decided to shut down seven nuclear power plants and is planning to return to previous concepts of an early phasing out. Instead of nuclear power, the government wants a further increased use of renewable energy sources in order to abide with designated climate protection goals by avoiding greenhouse gas emissions of conventional power plants. However, the integration of

Please cite this article as: Praktiknjo, A., Hähnel, A., Erdmann, G. (2011): Assessing energy supply security: Outage costs in private households. In: Energy Policy, 39: 7825-7833.

http://dx.doi.org/10.1016/j.enpol.2011.09.028 
growing shares of renewable energy sources into existing electricity systems is problematic because of two issues in Germany:

- The most relevant of these facilities do not generate power when the demand for it is given but only at times when nature's force is available (the wind is blowing, or the sun is shining).

- In Germany electricity from wind power is generated in the north close to the shore whereas electricity consumers are more concentrated in the south and in the west.

For a successful integration of a great share of renewables it is, therefore, necessary to either change the present power systems by including modern infrastructure with transmission lines and energy storages or to accept power outages.

To change present electricity systems that were developed over a century to what they are now requires a lot of time and is also expensive. In the meantime, issues of service reliability can arise if the gap between the pace of the expansion of renewables and the pace of the power system change gets wider and wider.

Nonetheless, the integration of renewables or a phasing out of nuclear power is not the only challenge to power supply security. Other concerns are raised because of recent issues like geopolitical conflicts (e.g. Russia-Ukraine in 2009), the threat of global terrorism or cyber terrorism (e.g. Stuxnet in 2010-Baker et al. (2011)) or the growing scarcity of conventional energy sources or the increasing global energy demand due to the growth of the world population and industrialization.

One of the possibilities to improve energy supply security is the holding of energy reserves. However, electricity is an energy carrier that is not storable. Therefore, the security of electricity supply simultaneously requires the physical availability of primary energy carriers, sufficient conversion capacities and reliable transport as well as distribution systems whenever needed.

Power outages can be a serious issue for modern societies. When examining the needs of human beings as illustrated in Maslow's Hierarchy of Needs (see Fig. 1), many of those basic needs are dependent on electricity.

Because of its importance, energy security is also one of the three key objectives of energy policy along with affordability and environmental sustainability (see Fig. 2). Energy policy measures can lead to a competitive standing between the three goals. For this reason, it is necessary to assess the impacts of energy policy measures on all of the three goals. To assess and compare these impacts on the different goals quantification in a common unit is helpful (e.g. from tons of $\mathrm{CO}_{2}$, Euros, outage durations, etc.). One possible common unit for quantification are monetary units as used in cost-benefit analyses. 


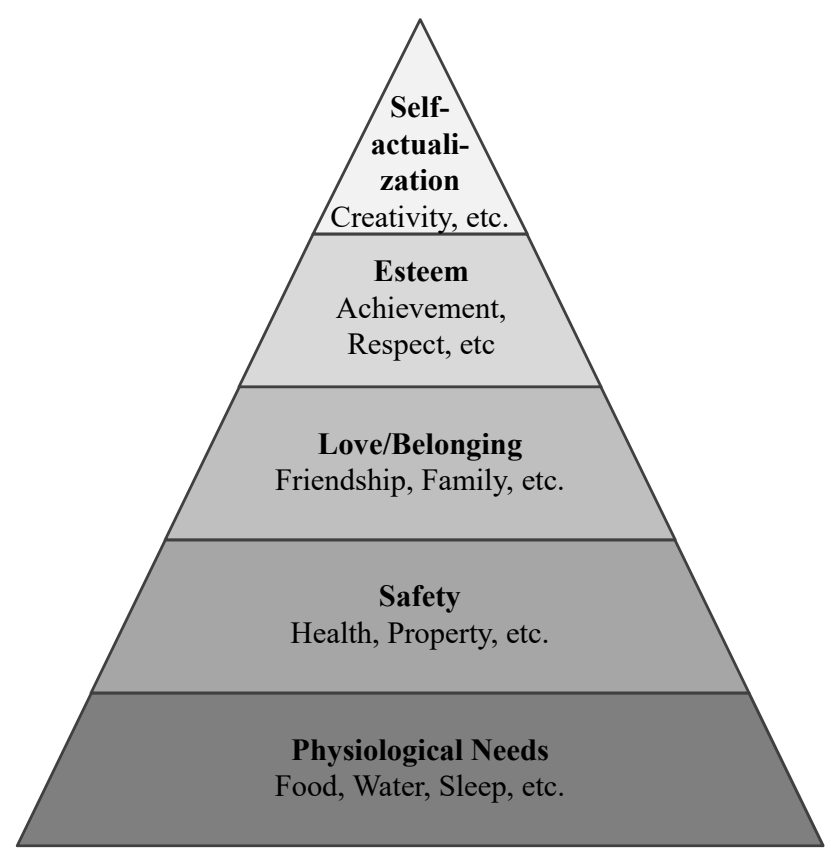

Figure 1: Maslow's Hierarchy of Needs, Maslow (1943)

Stern (2007) has contributed to a quantification of environmental sustainability by linking impacts on the environment to impacts on the economy and comparing them in monetary units. His contribution can assist policy makers, for example, when determining improvements regarding environmental sustainability with respect to economic consequences.

The goal of this paper is to contribute to the quantification of energy security by linking impacts on energy security to impacts on the economy. For this, a model to estimate the monetary consequences of power outages is proposed in this paper by analyzing the Value of Lost Load (VoLL). The particular focus in this work is put on the estimation of outage cost for private households. Outage cost estimations are particularly important when deciding on investments to improve supply security (e.g. additional transmission lines) in order to compare costs to benefits. But also, other policy decisions on measures that have direct or indirect consequences for the supply security (e.g. a phasing out of nuclear energy) need to be based on results from outage cost estimations. An electricity system is optimal from an economic point of view if the long-term marginal benefits from avoided cost due to avoided power interruptions become equal to the long-term marginal cost of improving service reliability.

Costs due to damages caused by power interruptions are known as Value of Lost Load (VoLL) in the literature. The VoLL is a figure that represents the average cost of unsupplied electricity in monetary units per unit of electricity (in many cases, kilowatt-hours $(\mathrm{kWh})$ ). In markets in which supply fails to satisfy demand, a loss of welfare is the consequence because of losses of consumer and producer surpluses. According to Stoft (2002), VoLL represents the average cost to consumers per unit of unserved electricity due to outages. The VoLL can, therefore, be considered as the average loss of Consumer Surplus (CS) per unit of Electricity Consumption (EC) (see Fig. 3). The demand for electricity is relatively inelastic as indicated by Erdmann and Zweifel (2007). An inelastic demand leads to high losses of consumer 
surplus. This also explains the reason for the VoLL being considered significantly higher than the actual price for electricity.

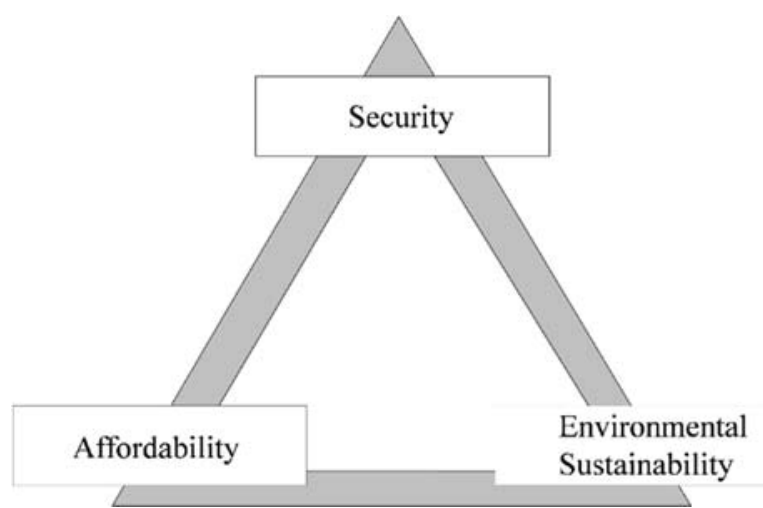

Figure 2: Goals of Energy Policy, Erdmann and Zweifel (2007)

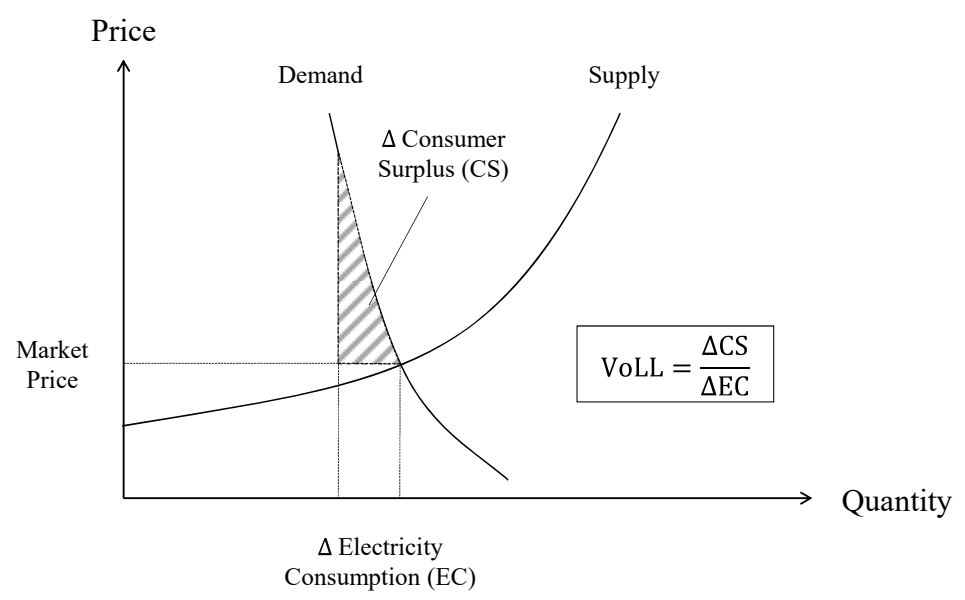

Figure 3: Electricity Market and Value of Lost Load

\section{Cost of Power Outages}

\subsection{Disaster economics}

Long and widespread power interruptions can lead to disasters, as stated by Wolf (2011). As discussed further above, electricity has become a vital resource in the 21st century. Therefore, it is not surprising that instruments to quantify consequences of power interruptions can be found in the science field of disaster economics. The following section discusses the fundamentals of disaster economics to enable a better understanding of studies on the subject of disaster costs.

Just as disasters can affect individuals in different areas (health, assets, comfort, etc.) blackouts can affect electricity consumers in different areas as well. To ensure comparability within an assessment of consequences between individuals, it is necessary to quantify the damages in a common unit. To do so, figures of conversion for the different damage units into a common unit are required. Because many decisions are based on cost figures due to fixed available budgets, monetary units are usually chosen to quantify damages. According to Berg, et al. (1994), disasters can 
affect society in five different categories. These categories are economy, quality of life, institutions, environment and health and life. A large-scale power interruption can cause damages in every one of these five categories. For example, business companies may not be able to operate and generate profit, private households and individuals may not be able to enjoy their leisure and comfort, public administrations may be hindered from doing their work, water treatment plants may not be able to cleanse the water and medical supply in hospitals may not work properly. A direct monetary assessment of damages in the category of economy is possible because economic values can be expressed in monetary units, and damage to those values is equal to cost. It is more complicated, however, to assess values in monetary units within the other four categories. A monetary assessment of these values requires a convertibility of how many units of damage in one category equal one unit of damage in another category. For further literature concerning this topic, see Berg, et al. (1994).

Furthermore, the consequences of disasters, such as large blackouts, can be clustered as direct and indirect, see Frontier Economics (2008). Direct damages of disasters lead to a loss of value, whereas indirect damages result in a loss of opportunity. The difference of asset-values in a state without and with blackouts represents direct costs. These costs need to be paid to return to the state of the pre-blackout condition. An example of direct cost is the cost for replacement of spoiled food in refrigerators after a long blackout. Indirect costs are the costs for the loss of opportunities such as profit that could have been made had there been no disaster. For example, an industrial producer is not able to produce during a power interruption. This does not result in a direct loss of assets but causes the producer to lose profit. Direct and indirect costs are graphically illustrated in Fig. 4.

Damages are in general monetarized with the Willingness To Pay (WTP) which is the maximum an individual would be willing to pay in order to avoid the damage. The basic concept of the WTP goes back to Arrow (1971) and Pratt (1964) (see equation below). In this concept, the WTP can be separated into a risk-neutral and a risk-averse component. The risk-neutral component equals the expected extent of damage $\mu$. Risk-neutral decision makers are willing to spend money to avoid damage to the extent of the expected value loss due to the possible damage. The risk-averse component of the WTP consists of the statistical spread of the expected extent of damage $\sigma$ and the readiness to take risks as well as a risk aversion $a v$, which can be derived from individual preferences and utilities. Risk-averse decision makers are willing to spend more money to avoid losses that have increasing risks. Some studies on the VoLL only analyze the expected extent of damage and make, therefore, a riskneutral assessment, whereas other studies analyze the actual WTP of consumers, which represents a risk-averse assessment.

$$
\begin{array}{cc}
W T P=\mu+\frac{A R A}{2} \sigma^{2} & \text { with } \quad A R A=-\frac{U^{\prime \prime}}{U^{\prime}} \\
\swarrow & \searrow \\
\text { risk-neutral } & \text { risk-averse }
\end{array}
$$


with $\mu$ is the expected damage (monetary unit); ARA is the Arrow-Pratt measure for absolute risk aversion (1/monetary unit); $\sigma^{2}$ is the Variance as a level for risks (monetary unit ${ }^{2}$ ) and $U$ is the Utility function.

Disaster cost studies and, therefore, outage cost studies as well, can be classified according to three factors: society, consequences and risks. Based on these factors, the classification of disaster cost studies can be illustrated in a three-dimensional diagram such as the one presented in Fig. 5.

$\underline{\text { Direct Costs }}$

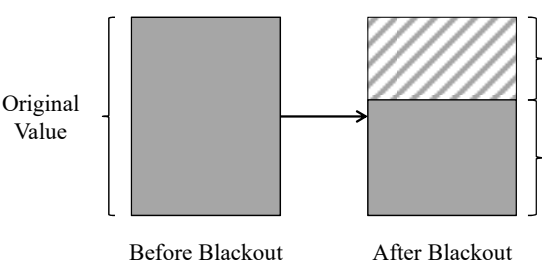

$\underline{\text { Indirect Costs }}$

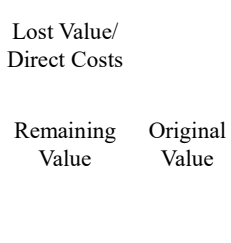

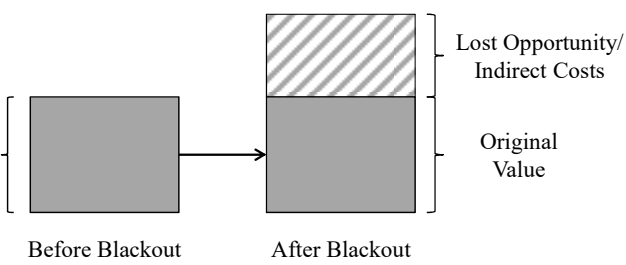

Figure 4: Direct and Indirect Costs

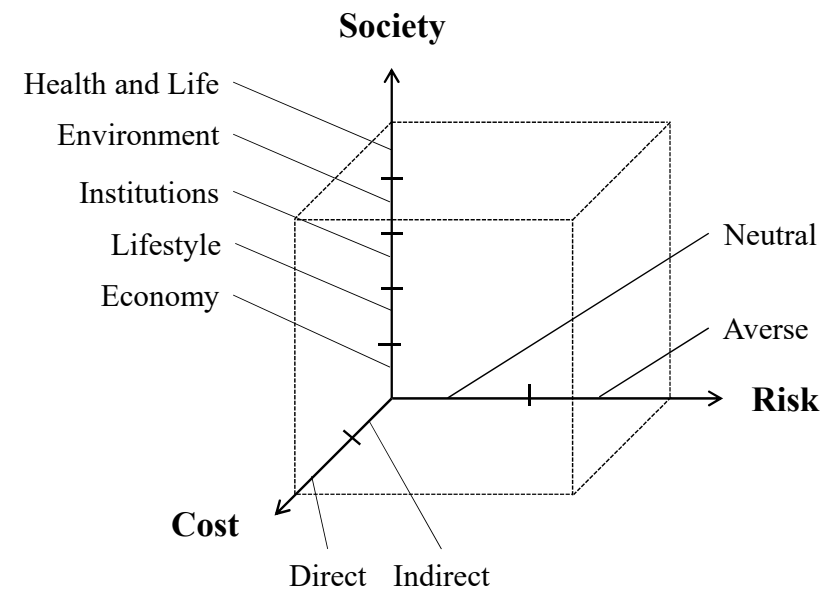

Figure 5: Three-Dimensional Classification of Studies on Disaster Cost

\subsection{Previous outage cost estimation studies}

There have been several international studies on outage cost. In a literature review conducted within this paper, 21 studies examining the VoLL for private households were identified. With an average of $9.39 € / \mathrm{kWh}$ and a standard deviation of 14.72 $€ / \mathrm{kWh}$, a comparison of the data reveals a wide range of results. The cost figures of the studies found in the review are shown in Table 1.

The costs of blackouts can be analyzed using different methods that focus on different aspects of interruption damages. Thus, an explanation for the variations in the results can be found in the difference of these analyzed aspects. Various methods were used in past studies to identify the VoLL. According to Sullivan and Keane (1995), the methods can generally be allocated into three types: methods based on macroeconomic indicators, market-based methods and survey-based methods. 
Studies based on macroeconomic indicators rely on electricity as an input factor and on macroeconomic indicators (such as the gross domestic product) as output data. Due to the statistical origin of this data, the conclusions reached by these studies are not limited to specific blackout circumstances but are instead applicable to more general situations. These studies, generally, do not take different individual blackout factors into account, and neglect direct damages (see the following section).

Market-based studies quantify the VoLL by analyzing consumer preferences on the basis of observations of real consumer choices made in the past regarding service reliability. The observations can be either ex-ante or ex-post of power outages. Because market-based studies rely on actual economic choices, their results are considered by Sullivan and Keane (1995) to possess high validity. However, the degree of freedom in market-based studies is limited because results are derived from choices based on available alternatives concerning service reliability and cost.

Studies based on surveys from interviewed consumers determine outage costs by analyzing responses to questions regarding preferences and choices. In these surveys, hypothetical power outage scenarios are used to collect the necessary data. The consumers are asked to either directly estimate outage cost or to choose between different scenarios in which interruption costs are later derived from their choices (conjoint analysis). The advantage of survey-based studies lies in the freedom of the hypothetical scenarios. As a result of these survey-based studies, it is possible to take different outage conditions and consumer damage factors into consideration without being dependent on available alternatives or actual power outages. However, the results of these studies rely on subjective estimations and not on actual choices.

Table 1: Comparison of outage cost studies for residential consumers ${ }^{1}$

\begin{tabular}{llcc}
\hline Reference & Country & Method & Outage Cost (€/kWh) \\
\hline Anderson and Taylor (1985) & Sweden & Survey & 3.57 \\
Baarsma and Hop (2009) & Netherlands & Survey & 3.66 \\
Balducci, Roop et al. (2002) & USA & Survey & 0.18 \\
Bertazzi, Fumagalli et al. (2005) & Italy & Survey & 10.89 \\
Billinton and Wangdee (2000) & Norway & Survey & 0.55 \\
Bliem (2005) & Austria & Macroeconomic & 16.63 \\
Bliem (2008) & Austria & Survey & 5.30 \\
Burns and Gross (1990) & USA & Survey & 5.72 \\
de Nooij, Koopmansb et al. (2007) & Netherlands & Macroeconomic & 16.38 \\
Jenkins, Lim et al. (1999) & Mexico & Macroeconomic & 0.75 \\
Kjølle, Samdal et al. (2008) & Norway & Survey & 1.08 \\
Krohm (1978) & USA & Survey & 2.46 \\
Lawton, Sullivan et al. (2003) & USA & Survey & 7.80 \\
Tol (2007) & Ireland & Macroeconomic & 68.00 \\
Sanghvi (1982) & USA & Survey & 0.48 \\
Wilks and Bloemhof (2005) & Netherlands & Survey & 21.62 \\
\hline
\end{tabular}

\footnotetext{
${ }^{1}$ Outage costs in other currencies were first inflated to 2007 and were then converted into Euros. The necessary data were taken from International Monetary Fund, 2010. World Economic Outlook Database.
}

Please cite this article as: Praktiknjo, A., Hähnel, A., Erdmann, G. (2011): Assessing energy supply security: Outage costs in private households. In: Energy Policy, 39: 7825-7833. http://dx.doi.org/10.1016/j.enpol.2011.09.028 


\subsection{Influencing factors on outage Cost}

The extent of blackout damages is dependent on many factors. These factors can generally be divided into two categories. The first group of factors can be subsumed under factors related to the circumstances of the blackout, whereas the second group of factors can be classified as factors related to preferences and needs of the consumers.

\subsubsection{Blackout factors}

One of the factors influencing the extent of the damages is the duration of the power interruption. Although marginal damages may increase, they can also decrease with the duration of a blackout. For instance, food that needs to be kept at a certain temperature loses value or spoils with the duration of a power interruption. During an extended outage, however, consumers may get accustomed to circumstances and inconveniences with ongoing duration of an interruption.

Another factor that influences the extent of the damages is the point in time of a power outage. The extent of damage due to an interruption may differ according to the time of the day, the day of the week and the season. An interruption during the day usually has different consequences than an interruption during the night just as an outage on a weekday has different consequences than an outage on a weekend. This also applies to a blackout in the summer as compared to a blackout in the winter.

Other than the previously mentioned factors, the frequency of reliability problems can be considered to be an influential factor. It is assumed that societies are prepared unequally for electrical power interruptions depending on the frequencies of blackouts within a given society. Societies in countries that experience relatively frequent power interruptions are probably better prepared for blackouts than societies where interruptions rarely occur. For this reason, service providers sometimes give advance notices, if possible, to inform the customers about upcoming outages to reduce damages due to a lack of preparedness.

\subsubsection{Consumer factors}

Individual electricity consumers experience blackout damages unequally. The reason lies in the difference of dependencies regarding the availability of electricity. The role and importance of an uninterrupted supply varies according to personal needs, existing assets and individual preferences. The variety of consumer damage factors is broad. For residential consumers, they include hobbies, preferences regarding eating at home or eating out, the availability of electronic equipment, the existence of domestic animals, etc. Concerning the preferences, residential consumers use electricity generally as end consumers, whereas industrial or commercial consumers require electricity to add value and generate profit. Therefore, it is advisable to differentiate between groups of consumers in an analysis of outage cost so as to take at least basic similarities into account. The present paper focuses on residential consumers in private households and analyzes the impact of selected consumer factors.

Please cite this article as: Praktiknjo, A., Hähnel, A., Erdmann, G. (2011): Assessing energy supply security: Outage costs in private households. In: Energy Policy, 39: 7825-7833.

http://dx.doi.org/10.1016/j.enpol.2011.09.028 


\section{Estimating the Value of Lost Load}

\subsection{Chosen method}

For this paper, the VoLL is estimated on the basis of a macroeconomic model with a Monte Carlo simulation. This method makes a risk-neutral assessment of indirect damages caused by power interruptions. The chosen output for residential consumers is home activities. Home activities or non-working time can be classified as quality of life in reference to the categorization of affected areas in society as discussed in the section Disaster Economics. Electricity is considered, in this context, as a partially substitutable input factor for activities at home. The macroeconomic model is also applied for commercial and industrial consumers. The chosen output for those consumers is value added and can be classified in economic terms in regard to the references mentioned above. Outage cost for governmental consumers are also briefly analyzed with taxes as output. The analysis of public administration can be classified under institutions in the same reference. In these cases, it is assumed that electricity is a non-substitutable input factor.

This approach differs from previous macroeconomic studies on the VoLL in two aspects:

- With data of the time spent from over 35,000 individuals, an effect of substitution is considered for the loss of time for 32 home activities (see DESTATIS (2002)).

- Uncertainties associated with the chosen input data of the model are taken into account by using a Monte Carlo simulation.

In the previously mentioned cubic classification of studies, the chosen method for estimating the VoLL can be categorized as illustrated in Fig. 6.

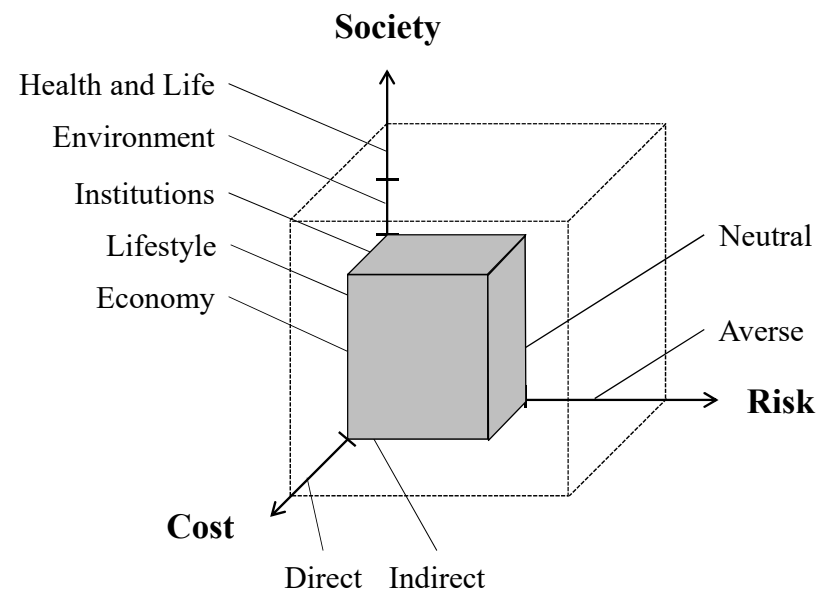

Figure 6: Categorization of the chosen method in the classification for disaster cost studies

As mentioned above, the loss of consumer surplus in the case of power interruptions is significantly higher than the prices for electricity. Positive effects due to money

Please cite this article as: Praktiknjo, A., Hähnel, A., Erdmann, G. (2011): Assessing energy supply security: Outage costs in private households. In: Energy Policy, 39: 7825-7833.

http://dx.doi.org/10.1016/j.enpol.2011.09.028 
saved because of avoided electricity charges are neglected for this reason in the following analysis of outage cost.

\subsection{Modeling and data preparation}

\subsubsection{Costs for residential consumers}

This paper assumes that several activities at home (or non- working activities) are not at all or only partially possible without the availability of electricity. Power outages, therefore, lead to a loss of opportunity to engage in certain activities. The present paper focuses on these losses as damages in private households based on the assumption that the entire electricity consumption of these consumers is used for activities of all kind outside of the work hours at home. These losses of opportunity can be categorized as indirect damages to quality of life as discussed in the section Disaster Economics.

The loss of activities at home cannot be directly assessed monetarily because time is not quantified in monetary figures. However, the theory of the Nobel Prize Winner Becker (1978) regarding multidimensional decisions with indifference curves makes it possible to valuate non-working time, see Fig. 7. One non-working hour corresponds to one hour of work less and, with that, the monetary compensation for one hour of work. This leads to Becker's conclusion that one hour of non-working time is financially equal to the compensation of an individual's hourly wage for work.

\section{Daily Hours of}

Leisure Time

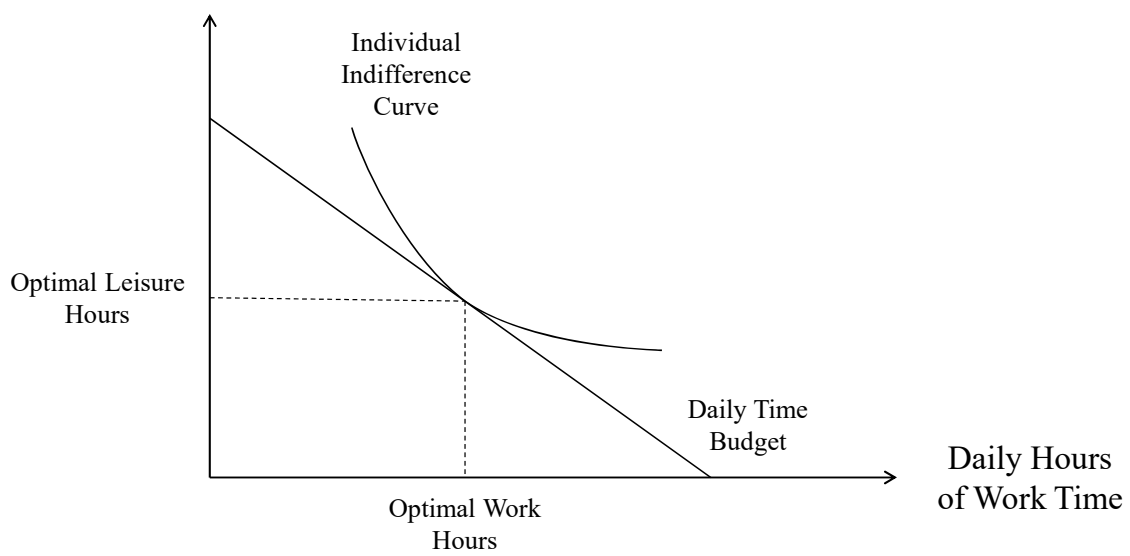

Figure 7: Indifference Curve between Work Hours and Leisure Hours

Hence, it is necessary to identify two consumer factors in this model to estimate the damage for private households in addition to the consumption of electricity: on the one hand, the time spent for activities at home that require the availability of electricity and, on the other hand, marginal hourly wages for an extra hour of work. Also, some of the lost activities can possibly be substituted with other activities that do not require electrical power. This needs to be considered in the analysis of the VoLL. The division of the monetized loss of activities at home by electricity consumption finally reveals a monetary value per kilowatt hours, which estimates the damages in private households due to power outages. 
The damages for lost activities at home on quality of life per individual are modeled as follows:

$$
V o L L_{\text {Residential } \_i}=d(\Delta t) \frac{w_{i}\left(1-f_{s u b_{i}}\right) \sum_{j=1}^{j=n} h_{f_{-} i j}}{E C_{i}}
$$

with $w_{i}$ is the hourly wages of individual $i$ (monetary unit/h); $f_{s u b \_} i$ is the factor of substitution for activities at home for individual $i$ with $f_{\text {sub_i } i} \in[0 ; 1] ; d(\Delta t)$ is the factor for the influence of outage duration with $d(\Delta t)>0 ; \Delta t$ is the outage duration with $t(\mathrm{~h})$; $h_{f_{-} i j}$ is the daily hours for non-working activity $j$ of individual $i(h) ; E C_{i}$ is the electricity consumption of individual $i(\mathrm{kWh})$.

To use this method, data with hourly wages are needed. There are 58,381 data entries for monthly wages and monthly workloads in hours in Germany that are available from DESTATIS (2002), which have been used to calculate average hourly wages. Due to the limited availability of data and as a simplification, these average hourly wages are used rather than marginal hourly wages. Marginal hourly wages for an additional hour of work are likely to be higher than average wages because salaries for hours for overtime may exceed average salaries.

Data regarding the time use of individuals are also necessary for this model. For this study, a dataset from DESTATIS (2002) with 35,673 day-entries on time use for the activities of 11,908 individuals was taken. However, it is problematic to use data from those who do not work because this model prices the non- working time of individuals with their hourly wages. A pricing of these individuals' time with zero monetary units per hour would result in an underestimation of the value of their time. On the contrary, to price the free time of persons who do not work with the wages of working people would be an overestimation. For this reason, it seemed reasonable to create a smaller sample for time use by excluding individuals who do not work from the total sample. The exclusion of entries containing data of children under the age of 16 and individuals with unemployment compensation as their only income source and the creation of average days to take the differences between weekdays and weekends into account results in a smaller sample. The new and smaller sample has a size of 9041 average day-entries from 9041 people with data on their time use.

Factors are determined for every individual to consider the previously mentioned possibility to substitute some activities at home in case of a power outage with other activities. These personal substitution factors are created by taking into account individual time-shares for the different daily activities. The activities were taken from the following seven areas: personal duties, chores, voluntary work, socializing, sports, hobbies and media. It is probable that an individual has considerable difficulty substituting activities with others in the event of a blackout if the majority of the individual's activities at home depend on the availability of electricity. Conversely, an individual with a generally low share of activities dependent on power supply can substitute his dependent activities much more easily in case of a blackout. Factors for the dependability on electricity $d_{j}$ of 32 activities at home with $d_{j}$ element of $[0,1]$ are estimated to take the previously described situation into 
account. Finally, a dataset with personal substitution factors $f_{\text {sub_i }}$ is derived for every individual from the combination of the time $h_{f_{-} i j}$ for non-working activities and the dependability factors $d_{j}$ from 32 activities (like the use of computers, cooking, listening to the radio, etc.) according to the equation presented below. Because the time use dataset stands at the origin of the individual substitution factors, their data sizes are equal-in the present case, it is equal to 9041.

$$
f_{\text {sub_i } i}=\frac{\sum_{j=1}^{j=n}\left(h_{f_{i j}} d_{j}\right)}{\sum_{j=1}^{j=n} h_{f_{-} i j}}
$$

with $f_{\text {sub } i} i$ is the factor of substitution for activities at home for individual $i$ with $f_{\text {sub_i } i} \in[0,1] ; h_{f_{-} i j}$ is the daily hours for non- working activity $j$ of individual $i(h)$ and $d_{j}$ is the factor for dependability with electricity for activity $j$ with $d_{j} \in[0,1]$.

Furthermore, a dataset with 52,061 entries on expenses per household for electricity and the sizes of those households is used as a basis to generate data on individual electricity consumption. The data are taken from the German New Economics Survey (EVS) from Research Data Centers (2003). The power consumption per household is then calculated by dividing expenses with the average electricity price for end consumers. Heinz (2010) estimates the average end consumer electricity price in Germany in 2003 with Eurostat (2009) and VDEW (2008) to have been at $18.44 €$-cents/kWh (value-added tax included). Data on average individual electricity consumption can then be obtained by dividing electricity consumption per household with the size of the households. To receive an undistorted sample of consumption per individual, the entries are multiplied according to the size of the households so that 126,540 data entries on individual electricity consumption are available for the VoLL model.

Thus, the three analyzed consumer factors for the damages are time use, wages and electricity consumption. With regard to the uncertainties and the statistical spread associated with these input factors of the model, a Monte Carlo simulation is conducted to process the data. The Monte Carlo simulation is a method in which uncorrelated input parameters $x_{1}, \ldots, x_{n}$ of a model $f\left(x_{1}, \ldots, x_{n}\right)$ are randomly drawn according to their frequency distributions with a sufficiently great number of runs. The simulation returns results of the model output with a frequency distribution. In this context, a Monte Carlo simulation with 10,000 runs is conducted to estimate and analyze the distribution of VoLL in private households. To perform a Monte Carlo simulation with 10,000 runs, it is necessary to, respectively, draw randomly and put back with every draw 10,000 data entries of the input parameters to calculate 10,000 output VoLL values. For a graphic chart of the Monte Carlo simulation see Fig. 8. The relationship between the service interruption's duration and outage costs for residential consumers has been analyzed in a survey by Praktiknjo (2011). The results for the influence of outage duration on outage costs are used for the model in this paper to carry out a sensitivity analysis for a variation in outage duration.

Please cite this article as: Praktiknjo, A., Hähnel, A., Erdmann, G. (2011): Assessing energy supply security: Outage costs in private households. In: Energy Policy, 39: 7825-7833.

http://dx.doi.org/10.1016/j.enpol.2011.09.028 


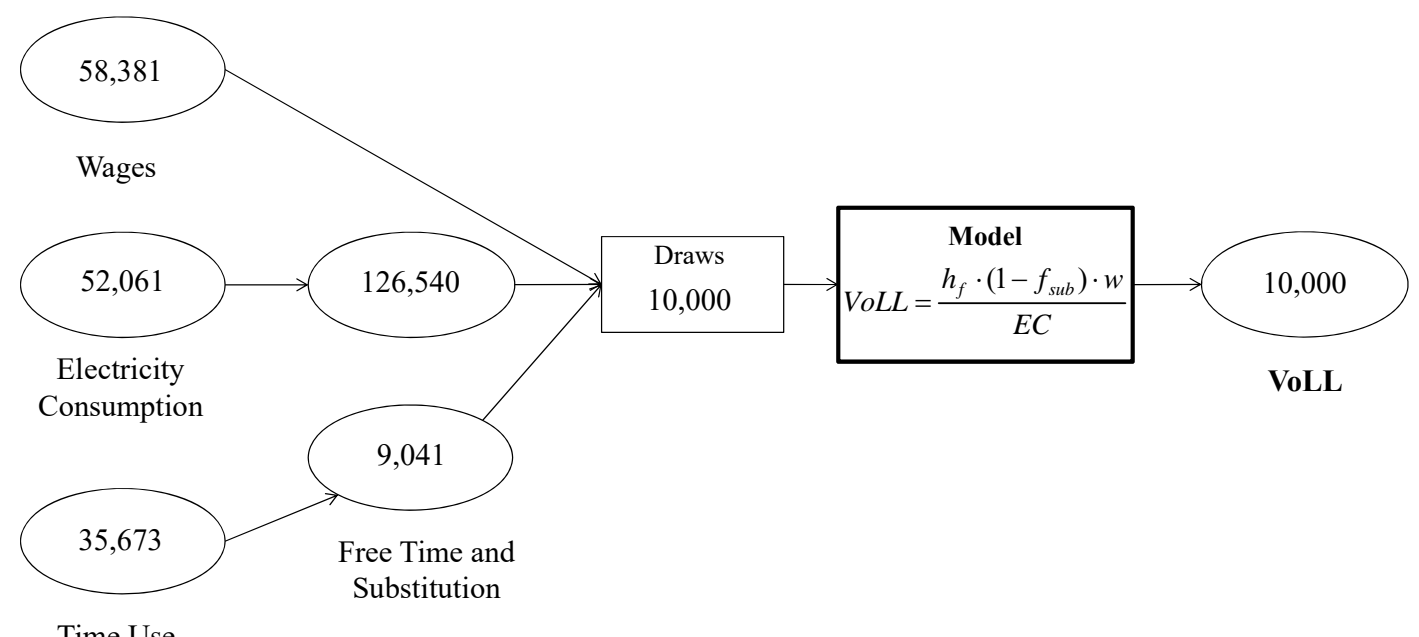

Time Use

Figure 8: Schematic diagram of the Monte Carlo simulation

\subsubsection{Costs for commercial, industrial and agricultural consumers}

Unlike damages due to the loss of activities, opportunity losses in the economy are assessed monetarily. With respect to this, it is assumed that it is impossible for commercial and industrial consumers to create added value without electricity as an input factor. Thus, these analyzed damages represent only indirect cost and fall under the category of economy. Electricity intensity as a quotient of electricity consumption and added value varies strongly in different economic sectors. Therefore, a differentiation is made between the following consumers of electricity:

- Industry;

- Commerce, Service and Transportation and

- Agriculture.

The distinction is reasonable and accounts for some basic differences mentioned in the section Consumer Factors.

The average VoLL in a sector is estimated by dividing the value added of a sector by its annual electricity consumption as shown in the

$$
V o L L_{C I_{-} S}=\frac{V A_{s}}{E C_{S}}
$$

with $V A_{s}$ is the value added of sector $s$ (monetary unit) and $E C_{s}$ is the electricity consumption for sector $s(\mathrm{kWh})$.

Sectorial electricity consumption in Germany is taken from the annual report of AGEB (2009). Data on value added per sector in Germany are available from DESTATIS (2008).

\subsubsection{Costs for public administrations}

A similar approach to the modeling of outage cost for commercial and industrial consumers is selected to estimate damages due to outages to public administration. In

Please cite this article as: Praktiknjo, A., Hähnel, A., Erdmann, G. (2011): Assessing energy supply security: Outage costs in private households. In: Energy Policy, 39: 7825-7833.

http://dx.doi.org/10.1016/j.enpol.2011.09.028 
this case, the total taxes paid are selected as the output rather than the value added. The VoLL for public administration is estimated with the equation shown below.

$$
V o L L_{P A}=\frac{T}{E C}
$$

with $T$ is the tax income in (monetary unit) and EC is the electricity consumption of the public administration in $(\mathrm{kWh})$.

The necessary data are available from AGEB (2009) and DESTATIS (2008).

\subsubsection{Total macroeconomic costs}

The VoLL for residential consumer, the VoLL for commercial consumer and the VoLL for public administration can be weighted with the shares of the respective annual electricity consumptions to calculate a total weighted average VoLL.

$$
V o L L_{a v g}=\frac{1}{E C} \sum_{i} V_{o L L} E C_{i}
$$

with VoLLavg is the average value of lost load in (monetary unit/kWh); EC is the annual electricity consumption in $(\mathrm{kWh}) ; V o L L_{i}$ is the value of lost load for consumer group $i$ in (monetary unit/kWh) and $E C_{i}$ is the annual electricity consumption of consumer group $i$ in $(\mathrm{kWh})$.

A well-established indicator to measure the quality of power service is the System Average Interruption Duration Index (SAIDI) which represents the average duration of an outage per consumer and year. For further references on this topic, see Dhillon (2007). By taking the average duration of blackouts for a consumer (SAIDI) together with the electricity consumptions and the average VoLL, the total estimated annual damages due to power interruptions can be determined.

The total costs can be calculated according to the equation shown below.

$$
C=V o L L_{\text {avg }} \frac{E C}{365 \cdot 24 \cdot 60} S A I D I
$$

with $C$ is the total annual macroeconomic cost for blackouts in (monetary unit); VoLLavg is the average value of lost load in (monetary unit $/ \mathrm{kWh}$ ); EC is the annual electricity consumption in $(\mathrm{kWh})$ and SAIDI is the average annual outage duration in (min).

\section{Results}

\subsection{Costs for residential consumers}

The results of the Monte Carlo simulation to estimate the cost of power outages in private households are illustrated in Fig. 9. We assumed interruption durations of one hour for the following results. The results need to be multiplied with the factor $d(\Delta t)$ explained below for other interruption durations.

On average, the VoLL $(1 \mathrm{~h})$ for residential consumers is equal to $15.70 € / \mathrm{kWh}$ in the present model with a median of $11.43 € / \mathrm{kWh}$. A Pearson type VI $(2.4712 ; 4.572$;

Please cite this article as: Praktiknjo, A., Hähnel, A., Erdmann, G. (2011): Assessing energy supply security: Outage costs in private households. In: Energy Policy, 39: 7825-7833.

http://dx.doi.org/10.1016/j.enpol.2011.09.028 
22.491) distribution appears to be a good fit for the results of the Monte Carlo analysis. The chi-squared test with 74 bins with equal probabilities has a result of 47.129 , which is, in this case, equal to a probability of 99.20 percent.

To measure the importance and impacts of the different input variables in the model, a sensitivity analysis is conducted by calculating standardized regression coefficients using Palisade's computer program @Risk. These coefficients show the impact of a one-standard-deviation change of the model's inputs on the model's output, the VoLL. They are standardized in order to ensure comparability so that these coefficients are element of $[-1 ; 1]$. The results of the analysis are illustrated in Fig.10. The influence of outage duration on outage cost is fitted (with a $R^{2}$ of 0.95 ) through the logarithmic function below which is graphically shown in Fig. 11.

$$
d(\Delta t)=1.0-0.21 \ln (\Delta t)
$$

with $d(\Delta t)$ is the factor for the influence of outage duration with $d(\Delta t)>0$ and $\Delta t$ is the outage duration with $\Delta t$ in (h).

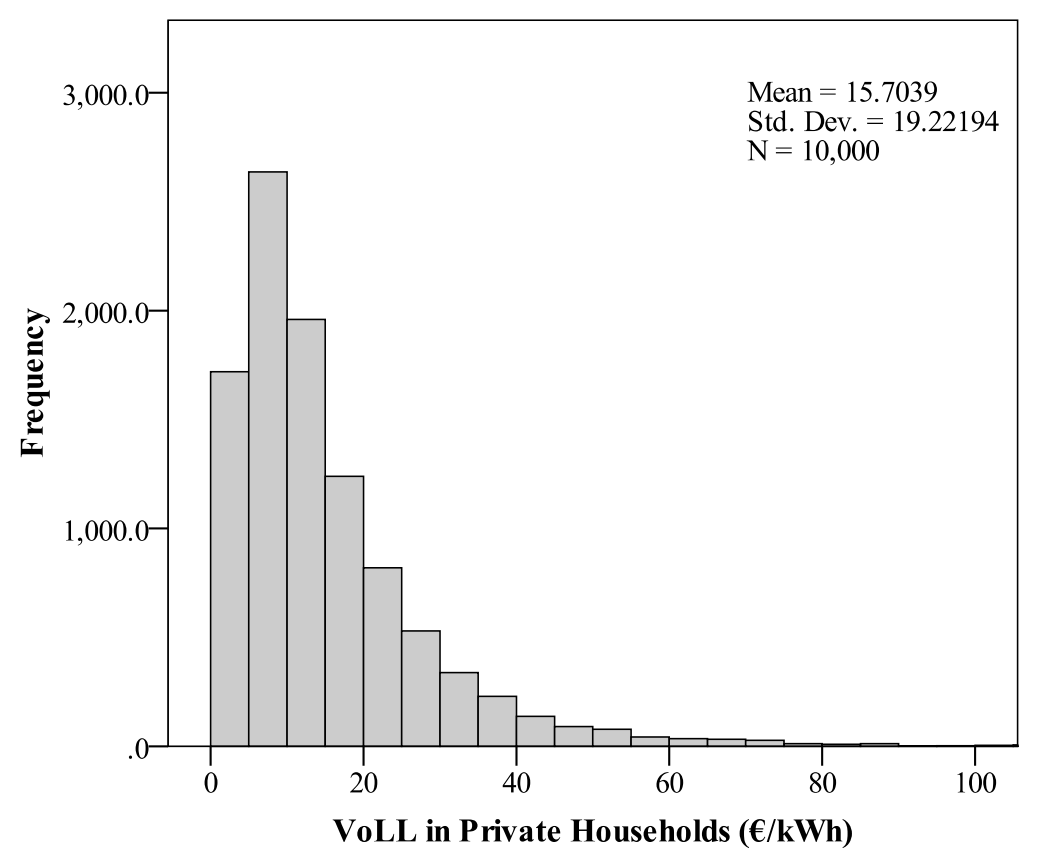

Figure 9: Results of the VoLL in private households of the Monte Carlo simulation

Please cite this article as: Praktiknjo, A., Hähnel, A., Erdmann, G. (2011): Assessing energy supply security: Outage costs in private households. In: Energy Policy, 39: 7825-7833.

http://dx.doi.org/10.1016/j.enpol.2011.09.028 


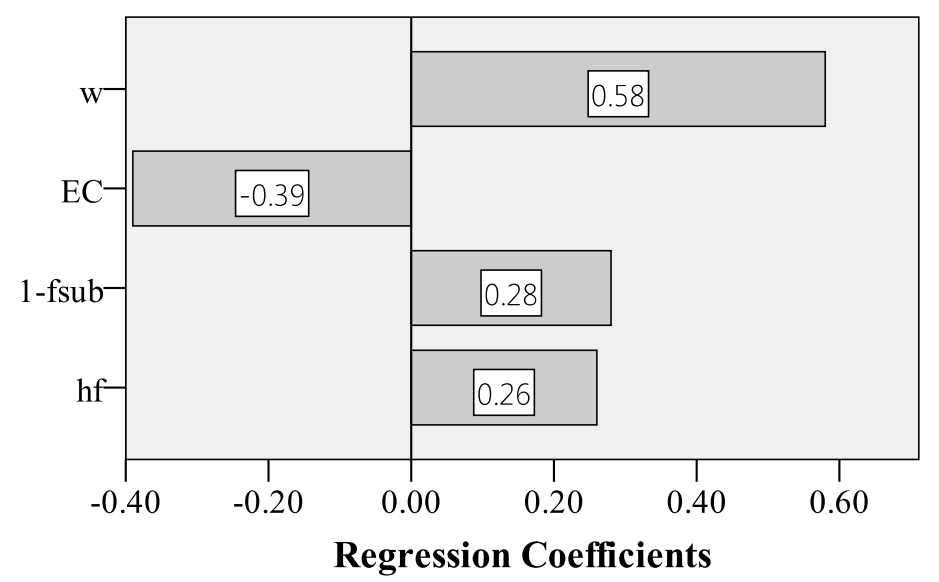

Figure 10: Sensitivity analysis of the VoLL model for private households

\subsection{Costs for commercial, industrial, agricultural and governmental consumers}

Results for the outage costs for commercial and industrial consumers are presented in Table 2 along with results for public administrations. The three analyzed sectors are agriculture, industry and commerce, service and transportation.

The average VoLL to the economy can be estimated by weighting the different VoLLs with the annual electricity consumptions of the respective sectors, which is, in this case, equal to $6.06 € / \mathrm{kWh}$. The VoLL for public administration is $5.53 € / \mathrm{kWh}$.

\subsection{Total macroeconomic costs}

The VoLLs for commercial consumers $(6.06 € / \mathrm{kWh})$, public administrations $(5.53$ $€ / \mathrm{kWh})$ and residential consumers $(15.70 € / \mathrm{kWh})$ are weighted with the respective shares of annual electricity consumptions (355.5, 45.5 and 140.2 TWh) as described previously to estimate the total average VoLL. The average VoLL is equal to 8.51 $€ / \mathrm{kWh}$ according to the available results for Germany in the year 2007.

According to the German Federal Network Agency (2007), the German electricity supply shows a relatively high degree of service reliability with a low SAIDI of 19.25 min of unplanned interruptions in 2007, excluding exceptional events. In comparison, the European average for 2007 was approximately 67.63 min (excluding Portugal) according to the Council of European Energy Regulators (CEER) (2008).

Accordingly, the average costs of blackouts in Germany in 2007 was $8.8 \mathrm{mn}$. $€ / \mathrm{min}$. Germany had a SAIDI of $19.25 \mathrm{~min}$ in 2007 excluding force-majeure events and 54.92 min including force-majeure events according to the Federal Network Agency (2007). This suggests that the annual outage cost for damages are equal to 169 and $481 \mathrm{mn} . €$ in 2007 (excluding and including force-majeure events, respectively).

A decrease in the service reliability to the average European level with a SAIDI of approximately $67.63 \mathrm{~min}$ (excluding Portugal and force-majeure events) according to the Council of European Energy Regulators (CEER) (2008) would be equivalent to an increase of more than 350 percent in outage cost and equivalent to $593 \mathrm{mn}$. $€$. 
Table 2: Results for outage costs for commercial, industrial and agricultural consumers

\begin{tabular}{lccc}
\hline & $\begin{array}{c}\text { Value added } \\
\text { / taxes in } \mathbf{1 0}^{\mathbf{9}} \boldsymbol{\epsilon}\end{array}$ & $\begin{array}{c}\text { Electricity consumption } \\
\text { in TWh }\end{array}$ & $\begin{array}{c}\text { VoLL } \\
\text { in } \mathbf{\epsilon} / \mathbf{k W h}\end{array}$ \\
\hline Agriculture & 19.93 & 8.5 & $\mathbf{2 . 3 4}$ \\
$\begin{array}{l}\text { Industry } \\
\text { Commerce, service }\end{array}$ & 653.20 & 255.3 & $\mathbf{2 . 4 9}$ \\
$\begin{array}{l}\text { and transportation } \\
\text { Public administration }\end{array}$ & 1.499 .05 & 91.7 & $\mathbf{1 6 . 3 5}$ \\
\hline
\end{tabular}

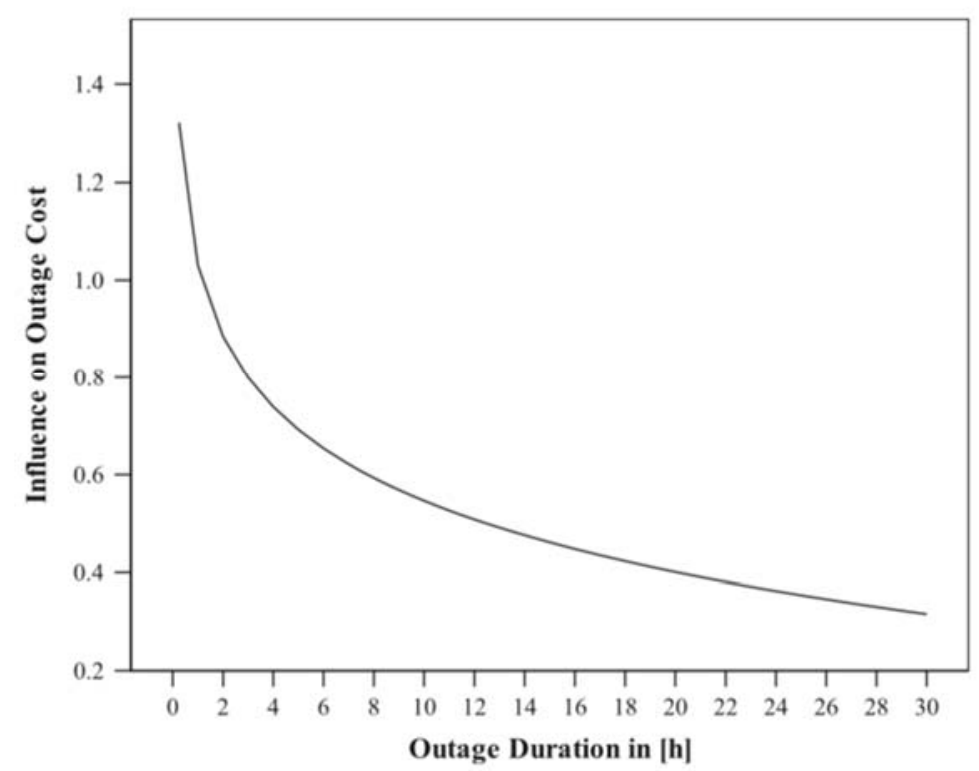

Figure 11: Influence of outage duration on outage cost

\section{Discussion}

The average result $(1 \mathrm{~h})$ for the residential VoLL in Germany with $15.70 € / \mathrm{kWh}$ is close to the results of the studies in the neighboring countries also applying macroeconomic approaches $(16.38 € / \mathrm{kWh}$ in the Netherlands and $16.63 € / \mathrm{kWh}$ in Austria). These cost figures point out that electricity supply security is an important good for the public and generally has an important role for residential consumers in industrialized countries. In times of global terrorism or threats of cyber-attacks, governments need to decide to what extent electricity grids need to be protected. The figures for outage cost help policy decision makers to decide upon investments in service reliability improvements by trading costs (investments) for benefits (avoided outage costs).

However, the approach followed in this study extends the previous macroeconomic studies by the use of a Monte Carlo simulation. The results of the Monte Carlo analysis reveal that the residential VoLL is strongly shifted to the left (average value of $15.70 € / \mathrm{kWh}$ and a median of $11.43 € / \mathrm{kWh}$ ). This means that a large percentage of the population has a relatively low VoLL whereas a small percentage of the population has a very high VoLL. The distribution of the VoLL in the population is

Please cite this article as: Praktiknjo, A., Hähnel, A., Erdmann, G. (2011): Assessing energy supply security: Outage costs in private households. In: Energy Policy, 39: 7825-7833. 
of high interest for future policy decisions especially with current debates about the integration of renewables into existing energy systems. One idea for the integration of renewables is the transition from an electricity system where the offer is flexible and the demand inflexible to a system where the demand is flexible (demand-side management). The present study shows the distribution of residential VoLL. With a fixed budget for increased demand flexibility, the potential for additional flexibility can be estimated in future studies by calculating the number of residential consumer that have lower interruption costs than the available budget. The right-skewed distribution of the residential VoLL suggests that potentials for demand-side management among residential consumers is significant.

The standardized correlation coefficients point out that the most influencing input factor for the residential VoLL model is hourly wage of a consumer followed by electricity consumption, the independence of home activities with electricity (substitution factor) and the daily time-budget for non-working activities in that order. It is likely that the continuous digitalization in private households will lead to a higher dependency on electricity for activities of all kind at home in the future. With that, the residential VoLL will increase as well.

The results also indicate that average outage cost per kilowatthour decrease with the duration of the interruption. Effects of substitutions can be a possible explanation for this observation. With increasing outage duration, the consumer might get more and more accustomed to the situation and chances to find other activities not requiring electricity will increase.

In the case of commercial and industrial consumer, the results for outage costs per kilowatthour are lower for sectors with relatively high electricity intensity compared to consumers in sectors with relatively low electricity intensity and vise versa. This does not mean that outages do fewer damages in sectors that have a relatively low VoLL, such as the industrial sector, compared to sectors that have a relatively high VoLL, like the commercial sector.

The analysis of the VoLL in private households is performed using a Monte Carlo simulation. Due to a limited availability of linked data, a possible correlation of the input variables of the model - hourly wages, home activities and electricity consumption - is neglected. It is, however, conceivable that there could be positive correlations between wages and electricity consumption and also between home activities and electricity consumption. It is also possible that a negative correlation between home activities and wages exists. If more complete data are available in the future, correlations of these variables should be verified, and the model, if necessary, adjusted to significant correlations.

Macroeconomic methods to estimate outage cost are limited to indirect cost. Total outage cost can therefore be higher than the results obtained in this analysis especially for industrial consumer. However, direct costs are somewhat limited for residential consumers so that obtained cost figures in these cases are a good indicator.

\section{Conclusion}

Germany's energy systems are on the brink of significant transformation (e.g. integration of renewables, nuclear phase-out, etc.). Important policy decisions

Please cite this article as: Praktiknjo, A., Hähnel, A., Erdmann, G. (2011): Assessing energy supply security: Outage costs in private households. In: Energy Policy, 39: 7825-7833.

http://dx.doi.org/10.1016/j.enpol.2011.09.028 
concerning electrical supply security have to be made in the near future. Costs and benefits of these decisions need to be quantified to make optimal decisions. Benefits of improved system reliability are avoided outage costs. This paper proposes a macroeconomic model to estimate costs of power outages by analyzing the VoLL. The main focus of this study is put on outage cost for electricity consumers in private households.

In this model, electricity serves as one of the input factors for the model. Value added is taken as output for commercial and industrial consumers, and a linear relationship between input and output is assumed. Non-working time is chosen as the output for residential consumer. Because some activities at home can be substituted with others in case of a blackout to a certain degree, factors are introduced to take these effects of substitutions into consideration. Individual factors for substitution are deduced from daily non-working hours and shares of activities dependent on electricity. The non-working time is converted into monetary values by using the theory of Nobel-Prize winner Becker (1978). The analysis of the VoLL in private households is performed using a Monte Carlo simulation to deal with uncertainties due to a multitude of individual conditions, preferences and choices. Because of limited data, possible correlations between input variables are neglected. These should be considered in future simulations if more complete data is available.

On average, the VoLL for commercial, industrial and governmental consumers in Germany is equal to $6.00 € / \mathrm{kWh}$. The results for residential consumers are reflected in the distribution obtained by the Monte Carlo simulation illustrated in Fig.9. Outage cost for these consumers in Germany amount to an average of $15.70 € / \mathrm{kWh}$ with a median of $11.43 € / \mathrm{kWh}$. A rightskewed Pearson type VI distribution (2.4712; $4.572 ; 22.491)$ fits the results well with a chi-square of 47.129 and a probability of 99.20 percent. Taking the total cost into consideration, the weighted average of blackout cost in Germany is $8.51 € / \mathrm{kWh}$.

Germany has one of the most reliable electricity systems in Europe. A decrease in the level of service reliability to the European average would lead to macroeconomic cost of more than $423 \mathrm{mn}$. $€$.

In general, monetary quantifications of blackout damages are meaningful because many public decisions are based on available budgets. Nonetheless, decisions solely based on valuations in monetary units can be questionable in some cases. For instance, it is possible that a purely monetary assessment of blackout consequences for a hospital in which the majority of patients are non-working persons results in a relatively low VoLL compared to a hospital in which the majority of the patients are working persons with high salaries. It can be ethically problematic to base certain decisions regarding supply security (such as in the above case) on monetary assessments alone. Thus, there are situations in which decisions regarding supply security should not be based on economic figures only. However, apart from these special cases, the knowledge of outage costs is important when making policy decisions with consequences to energy supply security. 


\section{References}

AG Energiebilanzen (AGEB), 2009. Energieverbrauch in Deutschland im Jahr 2008. Berlin.

Anderson, R., Taylor, L., 1985. The social cost of unsupplied electricity. A Critical Review Energy Economics 8 3, 139-146.

Arrow, K.J., 1971. Essays in the Theory of Risk-Bearing. North-Holland Pub. Co, Amsterdam.

Baarsma, B.E., Hop, J.P., 2009. Pricing power outages in the Netherlands. Energy Volume 34 (9), 1378-1386.

Baker, S., Filipiak, N., et al., 2011. In the Dark: Crucial Industries Confront Cyberattacks. Santa Clara, McAfee.

Balducci, P.J., Roop, J.M., et al., 2002. Electrical Power Interruption Cost, Estimates for Individual Industries, Sectors, and U.S. Economy. U.S. Department of Energy.

Becker, G., 1978. The Economic Approach to Human Behavior. University of Chicago Press, Chicago.

Berg, M., Erdmann, G., et al., 1994. Was ist ein Schaden? Polyprojekt Risiko und Sicherheit. Zurich, Eidgenössische Technische Hochschule Zürich.

Bertazzi, A., Fumagalli, E., et al., 2005. The use of customer outage cost surveys in policy decision-making: The Italian experience in regulating quality of electricity supply. CIRED 2005.

Billinton, R., Wangdee, W., 2000. Approximate methods for event-based customer interruption cost evaluation.

Bliem, M., 2005. Eine makroökonomische Bewertung zu den Kosten eines Stromausfalls im österreichischen Versorgungsnetz.

Bliem, M., 2008. Ökonomische Bewertung der Versorgungsqualität im österreichischen Stromnetz und Entwicklung eines Modells für ein QualitätsAnreizsystem. Klagenfurt, Alpen-Adria-Universität Klagenfurt.

Burns, S.J., Gross, G., 1990. Value of service reliability. IEEE Transactions on Power Systems 5 3, 825-834.

Council of European Energy Regulators (CEER), 2008. 4th Benchmarking Report on Quality of Electricity Supply 2008.

de Nooij, M., Koopmans, Bc., et al., 2007. The value of supply security: The costs of power interruptions: Economic input for damage reduction and investment in networks. Energy Economics 29 (2), 277-295.

DESTATIS, 2002. Time Use Survey 2001/2002. S. B. Deutschland. Wiesbaden. DESTATIS, 2008. Statistical Yearbook 2008. Wiesbaden, Statistisches Bundesamt Deutschland.

Dhillon, B.S., 2007. Applied Reliability and Quality: Fundamentals, Methods and Applications. London.

Erdmann, G., Zweifel, P., 2007. Energieökonomik. Springer-Verlag, Berlin.

Eurostat, 2009. Datenbank zu Energiestatistiken-Strompreise nach Art des Benutzers. Federal Network Agency, 2007. SAIDI-Wert Strom 2007. Retrieved 04.01.2011, from /http://www.bundesnetzagentur.de/DE/Sachgebiete/ElektrizitaetGas/Sonderth emen/SAIDIWertStrom2006_2007/SAIDIWertStrom06_07_node.htmlS. 
Frontier Economics, 2008. Kosten von Stromversorgungsunterbrechungen.

Heinz, B., 2010. Dynamische Simulation von stationären Brennstoffzellen im Liberalisierten Energiemarkt. Energy Systems. Berlin Institute of Technology, Berlin. International Monetary Fund, 2010. World Economic Outlook Database.

Jenkins, G.P., Lim, H.B.F., et al., 1999. Evaluation of an Expansion of the Electricity Transmission System in Mexico. Development Discussion Papers. Harvard, Harvard University.

Kjølle, G.H., Samdal, K., et al., 2008. Customer costs related to interruptions and voltage problems: Methodology and results. IEEE Transactions on Power Systems. Vol. 23, (3): 1030-1038.

Krohm, G., 1978. Costs of Interruptions of Electrical Service in the Commercial Sector, U.S. Dept. of Commerce. National Technical Information Service. Lawton, L., Sullivan, M., et al., 2003. A Framework and Review of Customer Outage Costs: Integration and Analysis of Electric Utility Outage Cost Surveys. B. Lab.

Berkeley, Environmental Energy Technologies Division.

Maslow, A.H., 1943. A theory of human motivation. Psychological Review 50 (4), 370-396.

Praktiknjo, A., 2011. Kosten von Stromausfällen für Private. emw Zeitschrift für Energie Markt Wettbewerb 2011 4, 20-24.

Pratt, J.W., 1964. Risk aversion in the small and in the large. Econometrica 32, 122 136.

Research Data Centres, 2003. New Economics Survey of Private Households (EVS) in 2003. Research Data Centres of the Federal Statistical Office and the statistical offices of the Länder.

Sanghvi, A.P., 1982. Economic costs of electricity supply interruptions: US and Foreign experience. Energy Economics 4 (3), 180-198.

Stern, N.H., 2007. The Economics of Climate Change: The Stern Review. Cambridge University Press, Cambridge.

Stoft, S., 2002. Power System Economics: Designing Markets for Electricity. WileyIEEE Press, Piscataway.

Sullivan, M.J., Keane, D.M., 1995. Outage Cost Estimation Guidebook. Electric Power Research Institute, San Francisco.

Tol, R.S.J., 2007. The Value of Lost Load. Security of Supply in Ireland, Sustainable Energy Ireland.

VDEW, 2008. Strompreise in Deutschland. V. d. E. B. W. e. V.

Wilks, M., Bloemhof, G., 2005. Reliability: Going Dutch? 3rd Reliability of Transmission and Distribution Networks, London.

Wolf, S., 2011. Wenn alle Lichter ausgehen. taz. Berlin. 